\title{
Cardiomyocyte progenitor cell mechanoresponse unrevealed: strain avoidance and mechanosome development.
}

\section{Citation for published version (APA):}

Mauretti, A., Bax, N. A. M., van Marion, M. H., Goumans, M. J. T. H., Sahlgren, C. M., \& Bouten, C. V. C. (2016). Cardiomyocyte progenitor cell mechanoresponse unrevealed: strain avoidance and mechanosome development. Integrative Biology, 8(9), 991-1001. https://doi.org/10.1039/c6ib00117c

\section{Document license:}

TAVERNE

DOI:

10.1039/c6ib00117c

Document status and date:

Published: 12/09/2016

\section{Document Version:}

Publisher's PDF, also known as Version of Record (includes final page, issue and volume numbers)

\section{Please check the document version of this publication:}

- A submitted manuscript is the version of the article upon submission and before peer-review. There can be important differences between the submitted version and the official published version of record. People interested in the research are advised to contact the author for the final version of the publication, or visit the $\mathrm{DOI}$ to the publisher's website.

- The final author version and the galley proof are versions of the publication after peer review.

- The final published version features the final layout of the paper including the volume, issue and page numbers.

Link to publication

\section{General rights}

Copyright and moral rights for the publications made accessible in the public portal are retained by the authors and/or other copyright owners and it is a condition of accessing publications that users recognise and abide by the legal requirements associated with these rights.

- Users may download and print one copy of any publication from the public portal for the purpose of private study or research.

- You may not further distribute the material or use it for any profit-making activity or commercial gain

- You may freely distribute the URL identifying the publication in the public portal.

If the publication is distributed under the terms of Article 25fa of the Dutch Copyright Act, indicated by the "Taverne" license above, please follow below link for the End User Agreement:

www.tue.nl/taverne

Take down policy

If you believe that this document breaches copyright please contact us at:

openaccess@tue.nl

providing details and we will investigate your claim. 


\section{Integrative Biology}

CrossMark \& click for updates

Cite this: Integr. Biol., 2016, 8, 991

Received 23rd June 2016, Accepted 24th August 2016

DOI: 10.1039/c6ib00117c

www.rsc.org/ibiology

\section{Cardiomyocyte progenitor cell mechanoresponse unrevealed: strain avoidance and mechanosome development $\dagger$}

\author{
Arianna Mauretti, ${ }^{\mathrm{ab}}$ Noortje A. M. Bax, $\stackrel{+}{\mathrm{ab}}^{\mathrm{ab}}$ Mieke H. van Marion, $\ddagger^{\mathrm{ab}}$ \\ Marie José Goumans, ${ }^{c}$ Cecilia Sahlgren ${ }^{\mathrm{ab}}$ and Carlijn V. C. Bouten ${ }^{\star a b}$
}

For emerging cardiac regeneration strategies, it is essential to know if and how cardiac stem cells sense and respond to the mechanical stimuli provided by their environment in the beating heart. Here, we study the response to cyclic strain of undifferentiated and predifferentiated human cardiomyocyte progenitor cells (CMPCs), as well as the formation and activation of the cellular structures involved in mechanosensing, that we termed 'mechanosome'. Once verified that the applied uniaxial cyclic strain $(10 \%, 0.5 \mathrm{~Hz})$ did not alter the cardiac lineage commitment and differentiation state of CMPCs, the cellular mechanoresponse to the applied strain was quantified by cellular orientation. While undifferentiated cells maintained their original (random) orientation, upon early cardiomyogenic differentiation (predifferentiated) CMPCs exhibited a distinct strain avoidance response after $48 \mathrm{~h}$ of cyclic straining. Interestingly, the mechanosome development and the activation of the mechanotransduction pathways also occurred with early cardiac differentiation of the CMPCs, regardless of the substrate or the applied cyclic strain. These results indicate that the mechanoresponse of CMPCs depends on the presence of a developed mechanosome, which only develops during early cardiomyogenic differentiation Our findings provide the first understanding of mechanotransduction in human CMPCs and as such can contribute to the improvement of cardiac regeneration strategies.

Insight, innovation, integration

The success of stem cell-mediated cardiac regenerative therapies is influenced by the ability of cardiac stem cells to respond to mechanical stimuli and integrate with the host tissue. Here, we show that the mechanosensitivity of cardiomyocyte progenitor cells (CMPCs) is developed during early cardiomyogenic differentiation, along with the formation and activation of the mechanosome, composed of integrin-mediated focal adhesions and actin stress fibers (SFs). Our results provide insight into the interactions of CMPCs with their mechanical environment, and can therefore help understanding the contribution of stem cells to cardiac function and contribute to the optimization of innovative therapies for the heart.

\section{Introduction}

Cardiovascular disease is among the leading causes of mortality in the Western world. Cardiac regenerative therapies focus on

\footnotetext{
${ }^{a}$ Department of Biomedical Engineering, Eindhoven University of Technology, PO box 513, Groene Loper, Building 15, Gem-Zuid 4.117, 5600 MB Eindhoven, The Netherlands. E-mail: c.v.c.bouten@tue.nl; Fax: +31 (0)40 2447355; Tel: $+31(0) 402473006$

${ }^{b}$ Institute for Complex Molecular Systems, Eindhoven University of Technology, Eindhoven, The Netherlands

${ }^{c}$ Department of Molecular Cell Biology and Center for Biomedical Genetics, Leiden University Medical Center, The Netherlands

$\dagger$ Electronic supplementary information (ESI) available. See DOI: 10.1039/c6ib00117c

\$ Authors contributed equally.
}

the repair and restoration of cardiac function with the use of stem or progenitor cells. In the human heart, several cardiac progenitor cell (CPC) populations have been identified. ${ }^{1}$ Among these, Sca1+ cardiomyocyte progenitor cells (CMPCs) have shown the ability to differentiate into the three cardiac lineages in vitro (cardiomyocytes, smooth muscle cells, and endothelial cells). ${ }^{2,3}$ After transplantation in the injured heart, CMPCs improve cardiac function and reduce scar formation. ${ }^{2}$ Our group has recently demonstrated that this can be attributed to the production and modulation of extracellular matrix (ECM) proteins ${ }^{4}$ to obtain a structurally organized, "healthy" ECM. Therefore, CMPCs represent a promising stem cell source for cardiac regenerative therapies. For successful regenerative outcomes the cells need to successfully integrate into the cyclically strained myocardium. 
Yet, very little is known of cardiac stem cell mechanosensitivity and mechanoresponse. By revealing the mechanisms that trigger mechanosensitivity in CMPCs, it may be possible to direct cell behavior towards the regeneration process.

In response to external mechanical cues, several differentiated cell types, such as endothelial cells, ${ }^{5,6}$ fibroblasts, ${ }^{7,8}$ and smooth muscle cells, ${ }^{9}$ have shown the ability to re-orient perpendicularly to the direction of applied cyclic strains in 2D setups. This behavior is called strain avoidance, and it shows the tendency of cells to align in the direction of minimum deformation of the cell itself and its mechanosensing components, thereby allowing cells to reside in areas of high strains in the body. ${ }^{10-12}$ While cell mechanoresponse in 3D is largely unknown, strain avoidance behavior is also exhibited in $2 \mathrm{D}$ by several stem cell types when subjected to cyclic strain, such as mesenchymal stem cells, ${ }^{13}$ bone marrow-derived progenitor cells, ${ }^{14}$ and adipose-derived stem cells. ${ }^{15}$ However, for CMPCs this behavior is unknown.

The process through which cells sense and respond to mechanical stimuli is called mechanotransduction, and the protein assemblies that mediate the signal transmission are known as focal adhesions (FAs). FAs are highly dynamic structures that form attachment sites of cells with the ECM. Normally, FAs are found at the end of actin stress fibers (SFs) ${ }^{16,17}$ and thereby they link the actin cytoskeleton with the ECM. Here, we refer to this cellular mechanosensing apparatus, in direct contact with the ECM, with the term "mechanosome". The term mechanosome was first introduced in the beginning of this century by Pavalko et al., ${ }^{18,19}$ to describe the load-bearing multi-protein complex in bone cells, which is composed of adhesion-associated and DNA-binding proteins. In the present study, the mechanosome is defined as the complex of cellular structures responsible for cell mechanosensing and the mechanoresponse. The complex consists of SFs as well as the integrin-mediated adhesions, including vinculin, integrin-linked kinase (ILK) and focal adhesion kinase (FAK). ${ }^{20}$ These adhesion complexes mediate bidirectional communication between cells and the ECM. ${ }^{21,22}$ Furthermore, integrins are also involved in the early formation of FAs, in which they form a stable complex with vinculin and talin. Vinculin is one of the best studied FA proteins, known for its important role in mechanotransduction. While its inactive form resides in the cytoplasm, vinculin acquires an extended conformation and localizes at the FAs upon activation. ${ }^{23}$ Another important player in mechanotransduction, especially for cardiac function, is $\mathrm{ILK}^{24}$ Upon integrin-ECM binding, FAK undergoes autophosphorylation at the Y397 tyrosine site (pFAK), leading to phosphorylation of a number of cytoskeletal proteins that are responsible for the maturation of FAs and the SFs. However, the CMPCs mechanosome and its key players are still unknown.

In the present study, we investigated the mechanoresponse of L9TB CMPCs to uniaxial cyclic strain, comparing undifferentiated cells with CMPCs in their early differentiated state (referred to as predifferentiated CMPCs). The applied cyclic strain caused strain avoidance of predifferentiated CMPCs but not of undifferentiated cells. Furthermore, the mechanosome developed upon early cardiomyogenic differentiation. A different seeding substrate or applied cyclic strain did not induce mechanosome development in undifferentiated CMPCs. Taken together, our results demonstrate that CMPCs gain the ability to respond to cyclic strain upon early cardiac differentiation, guided by the maturation and activation of the mechanosome. These results provide insight in the mechanobiology of CMPCs, and could help understand if and how these cells will react and adapt in the heart, which is an indispensable input for the development of new cardiac regenerative strategies.

\section{Materials \& methods}

\subsection{Culture of cardiomyocyte progenitor cells}

Human fetal CMPCs were isolated and cultured as described previously. ${ }^{25,26}$ In this study two primary cell isolations were used, the L3 and L6. The third group of cells, the L9TB CMPCs, was immortalized by lentiviral transduction of hTert and BMI-1. All CMPCs were cultured in SP++ growth medium consisting of M199 (Gibco)/EGM2 (3:1) supplemented with 10\% (v/v) fetal bovine serum (FBS) (Greiner bio-one), 1\% (v/v) non-essential amino acids (Gibco), and $1 \%(\mathrm{v} / \mathrm{v})$ penicillin/streptomycin (Lonza) on $0.1 \%(\mathrm{w} / \mathrm{v})$ gelatin (Sigma Aldrich)/PBS (Sigma) coated flasks.

\subsection{Differentiation of CMPCs}

To induce differentiation, starting on $\mathrm{d}_{\text {diff }} 1$ (Fig. 1A) CMPCs were treated with $5 \mu \mathrm{M}$ 5-azacytidine (Sigma) for $72 \mathrm{~h}$ in differentiation medium (IFDIFF) consisting of IMDM (Iscove's Modified Dulbecco's Medium)/Ham-F12 (1:1) (Gibco) supplemented with 2\% (v/v) horse serum, $10^{-4} \mathrm{M}$ ascorbic acid (A-A, Sigma), 1\% (v/v) non-essential amino acids, $1 \%(\mathrm{v} / \mathrm{v})$ insulin-transferrin-selenium (Lonza), and $1 \%(\mathrm{v} / \mathrm{v})$ penicillin/streptomycin. After $72 \mathrm{~h}$, the medium was changed, followed by transforming growth factor (TGF)- $\beta 1$ ( $1 \mathrm{ng} \mathrm{ml}{ }^{-1}$; Sigma) stimulation. Every 3 days, the medium with TGF- $\beta 1$ was refreshed (Fig. $1 \mathrm{~A}, \mathrm{~d}_{\text {diff }} 7, \mathrm{~d}_{\text {diff }} 10, \mathrm{~d}_{\text {diff }} 13$ ), as described previously. ${ }^{26}$ The differentiation protocol was carried on for 14 days before strain application and verified by gene expression prior to exposure to dynamic strain. After 14 days of differentiation, CMPCs reach an early differentiated state (predifferentiated CMPCs), whereby cardiac markers such as cardiac troponin $\mathrm{T}$ and myocardin are upregulated, and the sarcomeric component $\alpha$-actinin starts to be expressed, although sarcomeric organization cannot be observed at this point (Fig. S1, ESI $\dagger$ ). ${ }^{4}$ For the straining experiments, predifferentiated cells were seeded on Bioflex 6-well plates (Flexcell International Corporation, each well is made of a silicone membrane, Fig. 1B) at day 0 , and the differentiation protocol was continued up to day 2. Predifferentiated CMPCs were compared to undifferentiated CMPCs (Fig. 1A, $d_{\text {diff }} 0$ ).

\subsection{Cyclic straining}

Cyclic strain was applied using a FX-5000 Flexcell system (Flexcell International Corporation). Undifferentiated and predifferentiated L9TB CMPCs were seeded on collagen IV-coated Bioflex plates. Cells were seeded at $75 \%$ confluency and left for $24 \mathrm{~h}$ to allow attachment to the membrane. Uniaxial cyclic strain was applied by stretching the membranes on rectangular posts oriented in the $x$ direction $\left(90^{\circ}\right.$, Fig. 1B and D). Strains of 


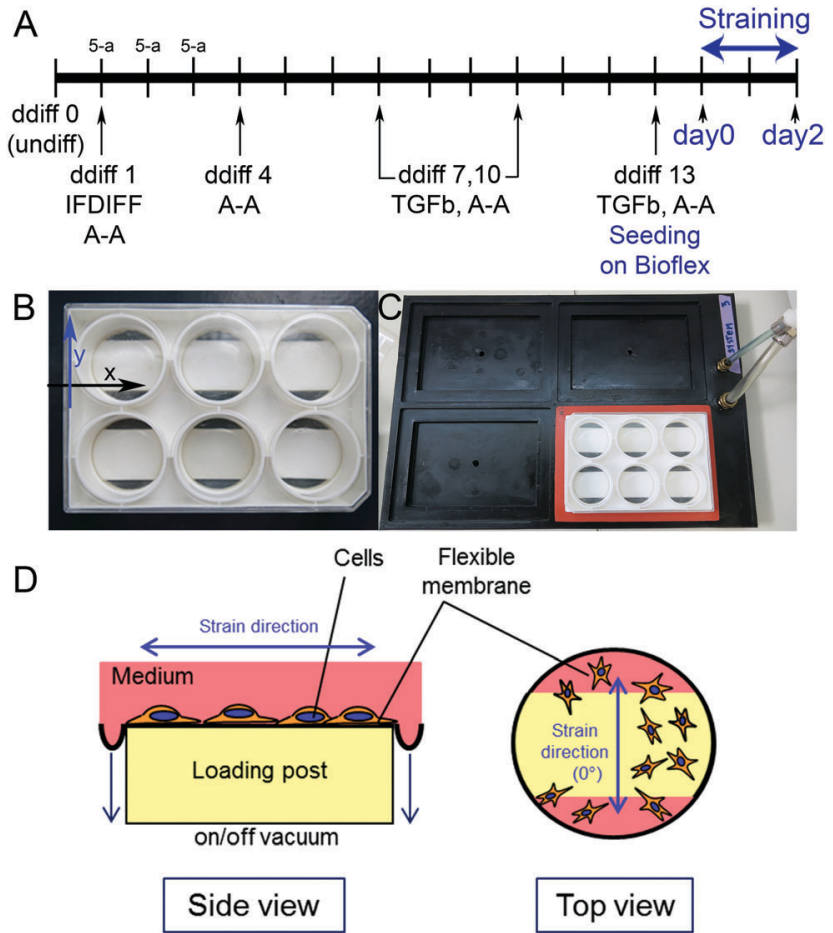

Fig. 1 Timeline and setup of the experiment. (A) Predifferentiated CMPCs were differentiated for up to 16 days starting on $d_{\text {diff }} 1$, by switching to differentiation medium (IFDIFF), enriched with ascorbic acid (A-A) and TGF $\beta 1$ (in the second week, $d_{\text {diff }} 7, d_{\text {diff }} 10$ ). After 13 days of differentiation $\left(d_{\text {diff }} 13\right)$, predifferentiated and undifferentiated CMPCs were seeded on Bioflex well plates and cultivated for $24 \mathrm{~h}$. The next day (day 0), uniaxial cyclic strain was applied for up to $48 \mathrm{~h}$ (day 2). (B-D) Mechanical loading was applied with a FlexCell device: the Bioflex plate (B) was placed on top of Teflon blocks oriented in the $x$ direction, in order to apply strain in the $y$ direction $\left(0^{\circ}\right.$, blue arrow). The plate was placed on the FlexCell system (C) for straining. The FlexCell device creates vacuum below the plate (D, side view), and the cells seeded in the Bioflex plate are stretched in the direction perpendicular to the orientation of the post ( $D, 0^{\circ}$, top view).

$10 \%(0.5 \mathrm{~Hz}$, sine wave) were applied for up to $48 \mathrm{~h}$ (day 2$)$ in the $y$ direction $\left(0^{\circ}\right.$, Fig. $1 \mathrm{~B}$ and $\left.\mathrm{D}\right)$.

Samples were analyzed at day 0 (before the onset of the straining protocol), after $24 \mathrm{~h}$ (day 1), and $48 \mathrm{~h}$ (day 2) of cyclic straining.
Unstrained samples, cultured on identical Bioflex plates and under the same conditions, were used as controls.

\subsection{Quantification of cell alignment}

The orientation response of L9TB CMPCs upon strain was determined from triplicates from three independent experiments. CMPCs were incubated for 20 min with $1 \mu \mathrm{g} \mathrm{ml} \mathrm{m}^{-1}$ calcein AM (Sigma). Before visualization, the medium was refreshed. Only cells in the central part of the wells, where the strain field was homogenous according to previous in-house calibration, were considered. Cell orientation was quantified with Fiji, using the Directionality plug-in (http://fiji.sc/wiki/index.php/Directionality) based on the Fourier transform (FFT) of each image by means of fitting a Gaussian to the FFT signal, measuring its peak position. For each group, 4 to 9 images were analyzed for each of the three independent experiments $(n=16-23)$.

\subsection{Immunofluorescence labeling}

The CMPCs that were cultured on cover glasses and Bioflex membranes were washed three times with Ham-F12 medium (Gibco) at $37{ }^{\circ} \mathrm{C}$, fixed in $3.7 \%$ (v/v) formaldehyde (Merck) for $15 \mathrm{~min}$, washed three times with PBS, and permeabilized with $0.5 \%(\mathrm{v} / \mathrm{v})$ Triton X-100 (Merck) in PBS for $10 \mathrm{~min}$. The Bioflex membranes were cut out of the plates with a scalpel, using the center of the membrane for immunofluorescence staining. Nonspecific antibody binding was blocked with $1 \%$ (v/v in PBS) horse serum incubation for $40 \mathrm{~min}$. Cells were then incubated overnight at $4{ }^{\circ} \mathrm{C}$ with primary antibodies in $10 \%$ (v/v in PBS) horse serum. Primary antibodies against FA proteins vinculin, integrin-linked kinase (ILK), and phosphorylated FAK (pFAK) were used to determine FA development. The cells were rinsed with PBS four times for $5 \mathrm{~min}$ and incubated for $1.5 \mathrm{~h}$ with secondary antibodies, and TRITC-labeled phalloidin for visualization of F-actin, in PBS. All used antibodies and dyes are listed in Table 1. Nuclei were stained with DAPI for $5 \mathrm{~min}$, after which cells were again washed four times with PBS and mounted on microscope glass slides with Mowiol. Except for primary antibody incubation, all incubation steps were performed at room temperature.

Table 1 List of used antibodies and dyes

\begin{tabular}{|c|c|c|c|c|c|c|c|}
\hline Antigen & Source & Cat. No & Isotype & Label & Species & Dilution IF & Dilution WB \\
\hline Vinculin (IF) & SA & V9131 & IgG1 & - & Mouse & $1 / 400$ & $1 / 500$ \\
\hline ILK & $\mathrm{SC}$ & sc-20019 & IgG2b & - & Mouse & $1 / 100$ & \\
\hline FAK (WB) & $\mathrm{BD}$ & bd-610087 & IgG1 & - & Mouse & $1 / 500$ & \\
\hline FAK (pY397) (IF) & $\mathrm{BD}$ & 611723 & IgG1 & - & Mouse & $1 / 100$ & $1 / 1000$ \\
\hline$\beta 1$-Integrin & $\mathrm{SC}$ & sc-53711 & IgG1 & - & Mouse & $1 / 400$ & \\
\hline Actin & $\mathrm{Ab}$ & $a b-3280$ & IgG1 & & Mouse & & $1 / 10000$ \\
\hline GAPDH & MI & CS207795 & IgG1 & - & Mouse & & $1 / 5000$ \\
\hline Mouse IgG1 & MP & A21121 & IgG1 & Alexa Fluor 488 & Goat & $1 / 300$ & \\
\hline Mouse IgG2b & MP & A21141 & IgG2b & Alexa Fluor 488 & & $1 / 300$ & \\
\hline Mouse IgG + IgM & $\mathrm{Pi}$ & 31457 & $\operatorname{IgG}+\operatorname{IgM}$ & HRP & Rabbit & & $1 / 10000$ \\
\hline Rabbit IgG & IV & A214228 & $\operatorname{IgG}(\mathrm{H}+\mathrm{L})$ & Alexa Fluor 555 & Goat & $1 / 300$ & \\
\hline Phalloidin & SA & P1951 & & TRITC & Amanita phalloides & $1 / 200$ & \\
\hline DAPI & $\mathrm{SA}$ & D9542 & & & & $1 / 500$ & \\
\hline
\end{tabular}

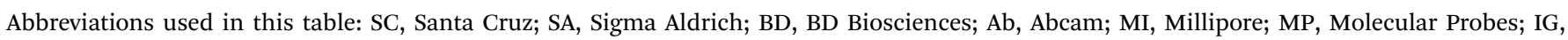
Invitrogen; Pi, Pierce; HRP, horseradish peroxidase. 


\subsection{Mechanosome development on silicone and glass substrates}

To observe the development of the mechanosome in undifferentiated and predifferentiated CMPCs during cell spreading and on different substrates, cells were seeded on: (a) collagen IV-coated Bioflex 6-well plates as purchased by the manufacturer, and (b) $13 \mathrm{~mm}$ diameter glass coverslips, placed in 24-well culture plates and sterilized with $70 \%(\mathrm{v} / \mathrm{v})$ ethanol, coated with $25 \mu \mathrm{g} \mathrm{ml} \mathrm{m}^{-1}$ collagen IV (Corning). Cells were seeded with a density of $1 \times 104$ cells per $\mathrm{cm}^{2}$, and fixed after $1 \mathrm{~h}, 6 \mathrm{~h}$ and $24 \mathrm{~h}$ following plating for immunofluorescence staining.

\subsection{Total Protein Isolation and Isolation of Cytoskeletal and Soluble Protein Fractions}

Total protein extracts of L3, L6 and L9TB CMPCs were obtained by lysing the cells in Ripa lysis buffer (Sigma-Aldrich) containing protease inhibitors (Sigma-Aldrich) $(n=6)$. Protein concentrations were determined using a Bicinchronic Acid (BCA) protein assay (Pierce). Total protein extracts were stored at $-80{ }^{\circ} \mathrm{C}$ until analysis.

Soluble and cytoskeletal bound protein fractions of L3, L6, L9TB CMPCs were isolated using the ProteoExtract ${ }^{\circledR}$ cytoskeletal isolation and enrichment kit (Millipore) ( $\mathrm{d}_{\text {diff }} 1 n=6 ; \mathrm{d}_{\text {diff }} 7$, $\left.\mathrm{d}_{\text {diff }} n=4 ; \mathrm{d}_{\text {diff }} n=5\right)$. In short, after washing the cells with cold PBS, soluble proteins were isolated using cellular extraction buffer (CEB). After washing with cytoskeletal wash buffer (CWB), nuclear proteins were isolated after $10 \mathrm{~min}$ incubation with nuclear extraction buffer (NEB). Cells were washed again with CWB and cytoskeletal proteins were isolated after scraping in cytoskeletal solubilization buffer (CSB). All buffers contained a protease inhibitor cocktail and sodium orthovanadate, included in the kit. To further solubilize cytoskeletal protein extracts of 14 days cultured CMPCs, lysates were sonicated 3 times for $10 \mathrm{~s}$ at an amplitude of 7 microns (Soniprep 150, Sanyo). Separate protein fractions are further referred to as soluble fraction (S), nuclear fraction (N) and cytoskeletal fraction (C). For comparison between fractions, equal volumes of the different fractions were used. To check for proper separation of the different fractions, samples were checked with Western blotting for GAPDH (only present in S and $\mathrm{N}$ ) and vimentin (only present in $\mathrm{C}$ ) (data not shown). Protein fractions were stored at $-20{ }^{\circ} \mathrm{C}$ until further analysis.

\subsection{Western blotting}

The level of focal adhesion development was semi-quantitatively examined in total protein extracts and separated protein fractions ( $\mathrm{S}$ and $\mathrm{C}$ ) by Western blotting for $\beta 1$-integrin and vinculin. Equivalents of $5 \mu \mathrm{g}$ total protein or $12.5 \mu \mathrm{L}$ of the separated protein fractions were size fractioned on a $10 \%$ polyacrylamide gel and blotted onto a Hybond PVDF membrane (Immobilon-P, Millipore). Non-specific binding sites were blocked with 5\% milk powder (ELK) in $0.1 \%$ PBS/Tween20. Membranes were probed with primary antibodies at $4{ }^{\circ} \mathrm{C}$ overnight, washed and subsequently incubated at room temperature with horse-radish peroxidase (HRP) labeled secondary antibodies for $1 \mathrm{~h}$ (for used antibodies and their dilutions see Table 1). For total protein extracts, GAPDH was used as loading control. For visualization, membranes were incubated with enhanced chemiluminescence substrate (Thermo Scientific Pierce), and bands were detected using the Proxima C16 Phi+ (Isogen) imager. Bands were quantified by determining the intensity of the bands $\left(\mathrm{INT}^{*} \mathrm{~mm}^{2}\right.$ with global background correction) using Quantity One image analysis software (Biorad, version 4.6.6).

\subsection{Statistical analysis}

Cell orientation data are presented as mean \pm standard deviation (SD; $n=16-23$ from 3 independent experiments). Western blot data are shown as mean \pm standard error of the mean (SD; $\mathrm{d}_{\text {diff }} 1: n=6, \mathrm{~d}_{\text {diff }}$ 7-14: $n=4$ from three independent experiments). Statistical analysis was performed using one-way ANOVA with Bonferoni post hoc test for multiple comparisons. Significance was assumed when $P<0.05$. Graphics and statistical analyses were performed with GraphPad Prism software (version 5.04).

\section{Results}

\subsection{CMPC strain avoidance is induced by differentiation}

The ability of CMPCs to sense and respond to mechanical cues was analyzed by applying uniaxial cyclic strain for $48 \mathrm{~h}$, and visualizing cell alignment with calcein staining. The early differentiation state was verified by gene expression and immunostainings of cardiac markers (Fig. S1, ESI $\dagger$ ). The applied strain had no influence on the CMPC cardiac lineage commitment and differentiation state, as demonstrated by the unchanged gene expression of cardiac markers following strain application (Fig. S2, ESI †). Before strain was applied (day 0), both undifferentiated and predifferentiated cells were randomly oriented (Fig. 2A and B). This random orientation was maintained throughout the experiment in the unstrained samples for both cell types (Fig. 2C, D, G and H). After 24 h (day 1), strained undifferentiated CMPCs displayed random orientation, although some cells, especially in the areas characterized by higher cell density, showed orientation perpendicular to the strain direction (Fig. 2E and M). After $48 \mathrm{~h}$ of strain (day 2), undifferentiated cells did not show a preferred orientation. However, in those areas where undifferentiated cells showed strain avoidance at day 1 , some reorientation at $90^{\circ}$ was observed at day 2 as well (Fig. 2I and O). Interestingly, strained predifferentiated CMPCs displayed random orientation at day 1 , regardless of cell density (Fig. $2 \mathrm{~F}$ and $\mathrm{M}$ ). In contrast, at day 2 strained predifferentiated CMPCs showed a distinct strain avoidance response, and re-oriented perpendicularly to the direction of applied strain (Fig. 2J and O). The amount of cells oriented at exactly $90^{\circ}$ was used as representative value of orientation for all groups to perform statistical analysis (Fig. 2P and Q). At day 2, the fraction of oriented cells was significantly different between strained undifferentiated and strained predifferentiated CMPCs $(P<0.001$, Fig. $2 \mathrm{P}$ and $\mathrm{Q})$. Moreover, a significant difference was observed between unstrained and strained predifferentiated CMPCs $(P<0.01$, Fig. $2 \mathrm{P})$. 

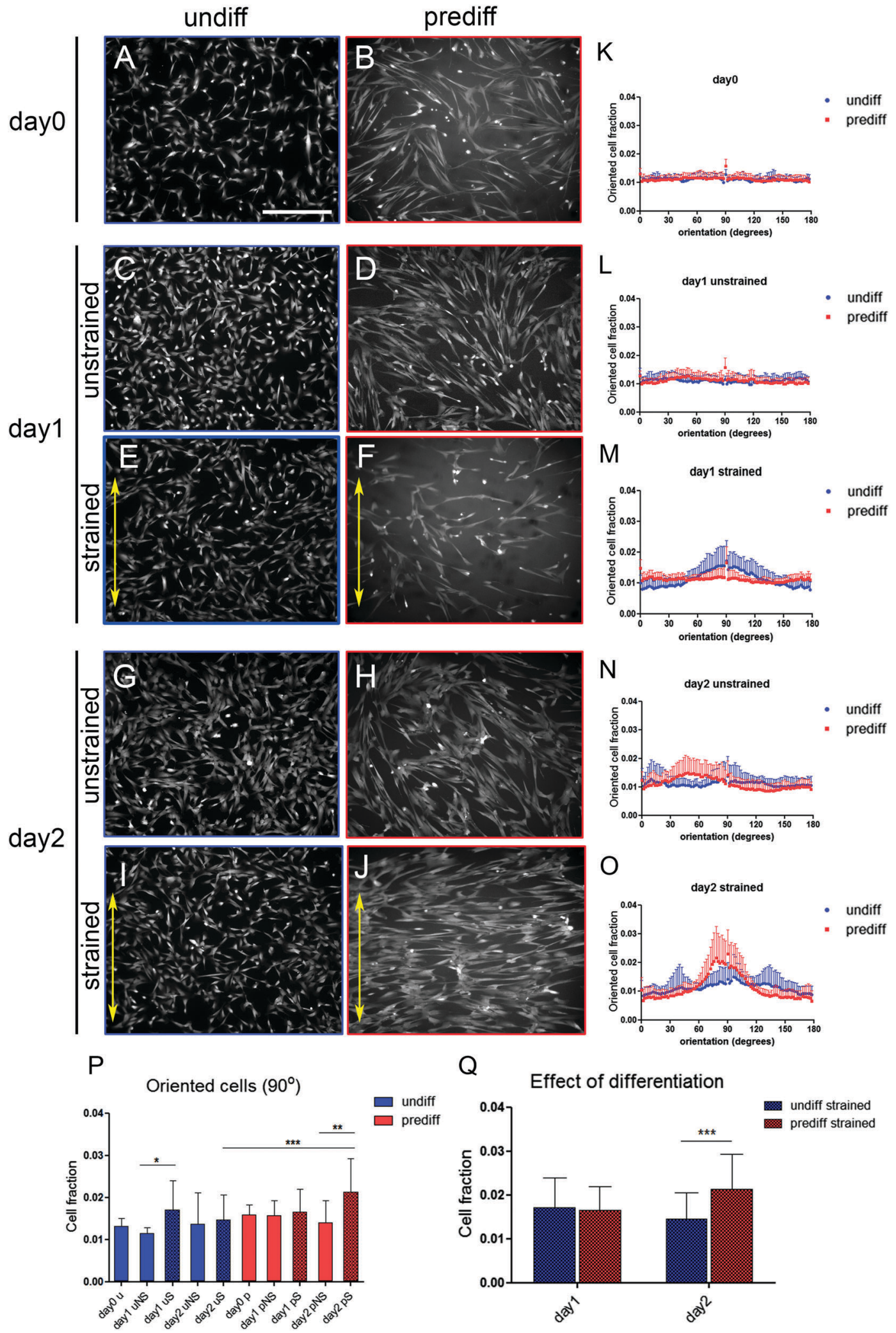

Fig. 2 CMPCs respond to cyclic strain upon differentiation. (A-J) Representative fluorescent images (calcein staining) of undifferentiated (undiff) and predifferentiated (prediff) CMPCs at day 0 , day 1 , and day 2 of strain (strain direction is indicated by the arrow, $0^{\circ}$ ). (K-O) Frequency distributions display the cell orientation corresponding to each group. While undifferentiated CMPCs (blue) do not respond to the strain, predifferentiated cells (red) show strain avoidance response at day 2. The fraction of cells oriented at $90^{\circ}(\mathrm{P}$ and Q) shows a clear strain avoidance response of predifferentiated CMPCs at day 2 ( $u$ = undifferentiated; $p=$ predifferentiated; $S=$ strained, patterned fill; NS = unstrained, solid fill). Scale bar indicates $400 \mu \mathrm{m}$. Results are expressed as mean $\pm \mathrm{SD}\left(n=16-23\right.$ from 3 independent experiments); ${ }^{*}=P<0.05 ;{ }^{*}=P<0.01 ;{ }^{* *}=P<0.001$. 
3.2 Differentiation but not strain induces the mechanosome development in CMPCs

The mechanosome plays a crucial role in cellular mechanotransduction; it includes integrins, FA proteins, and actin SFs. ${ }^{24,27,28}$ Upon application of forces to the cell, FA proteins at the cell-ECM adhesion sites, such as vinculin, ILK, and FAK, are activated, relocated to the FAs, and allow the cell to respond by modifying its actin cytoskeleton. ${ }^{29}$ Here, we examined the protein distribution of vinculin, ILK, and FAK, and the development of SFs in undifferentiated and predifferentiated CMPCs in response to cyclic strain. At day 0 (Fig. 3A-F), undifferentiated CMPCs showed an undeveloped mechanosome. These cells displayed a mainly cytoplasmic expression of FA proteins, with few small protein clusters localized at the cell edges, typical of immature adhesions (Fig. 3A, C and E). ${ }^{17,30}$ Staining for F-actin showed the presence of cortical and cytoplasmic actin, while no SFs were visible (Fig. 3A). Upon early cardiac differentiation (predifferentiated) CMPCs exhibited a more developed mechanosome. At day 0, the presence of mature FAs was demonstrated by the expression of all investigated FA proteins, distributed as clusters localized on the basal side of the cell and at the cell edges (Fig. 3B, D and F). Cortical and cytoplasmic actin with a few SFs were visible (Fig. 3B).

After one (day 1, Fig. 3G-R) and two days (day 2, Fig. 3S-AD) of straining, undifferentiated CMPCs still showed an immature mechanosome, with only small clusters of vinculin and absence of SFs (Fig. 3G, M, S and Y), and cytoplasmic expression of ILK (Fig. 3I, O, U and AA) and pFAK (Fig. 3K, Q, W and AC). Predifferentiated cells instead, exhibited FA clusters and well developed SFs (Fig. 3H, J, L, N, P, R, T, V, X, Z, AB and AD). In both cell types, slightly larger FAs were observed in unstrained samples (Fig. 3G-L, S-X), suggesting the presence of more stable adhesions, whereas strained samples displayed thinner and more elongated FA assemblies (Fig. 3M-R, Y-AD). Therefore, the applied strain does not seem to induce the development of the mechanosome.

\subsection{The CMPC mechanosome develops with differentiation regardless of the substrate characteristics}

To verify the differentiation-induced mechanosome development, we analyzed cell spreading and mechanosome development in undifferentiated and predifferentiated CMPCs seeded
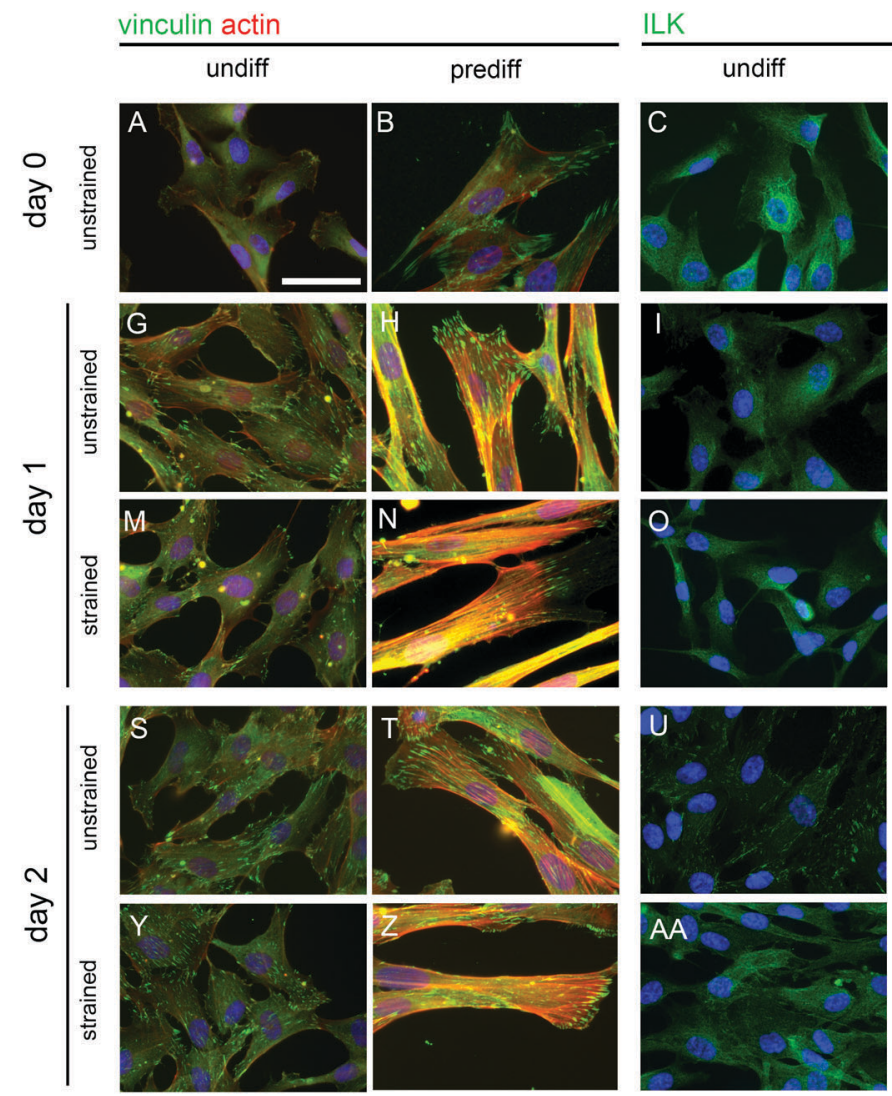

prediff
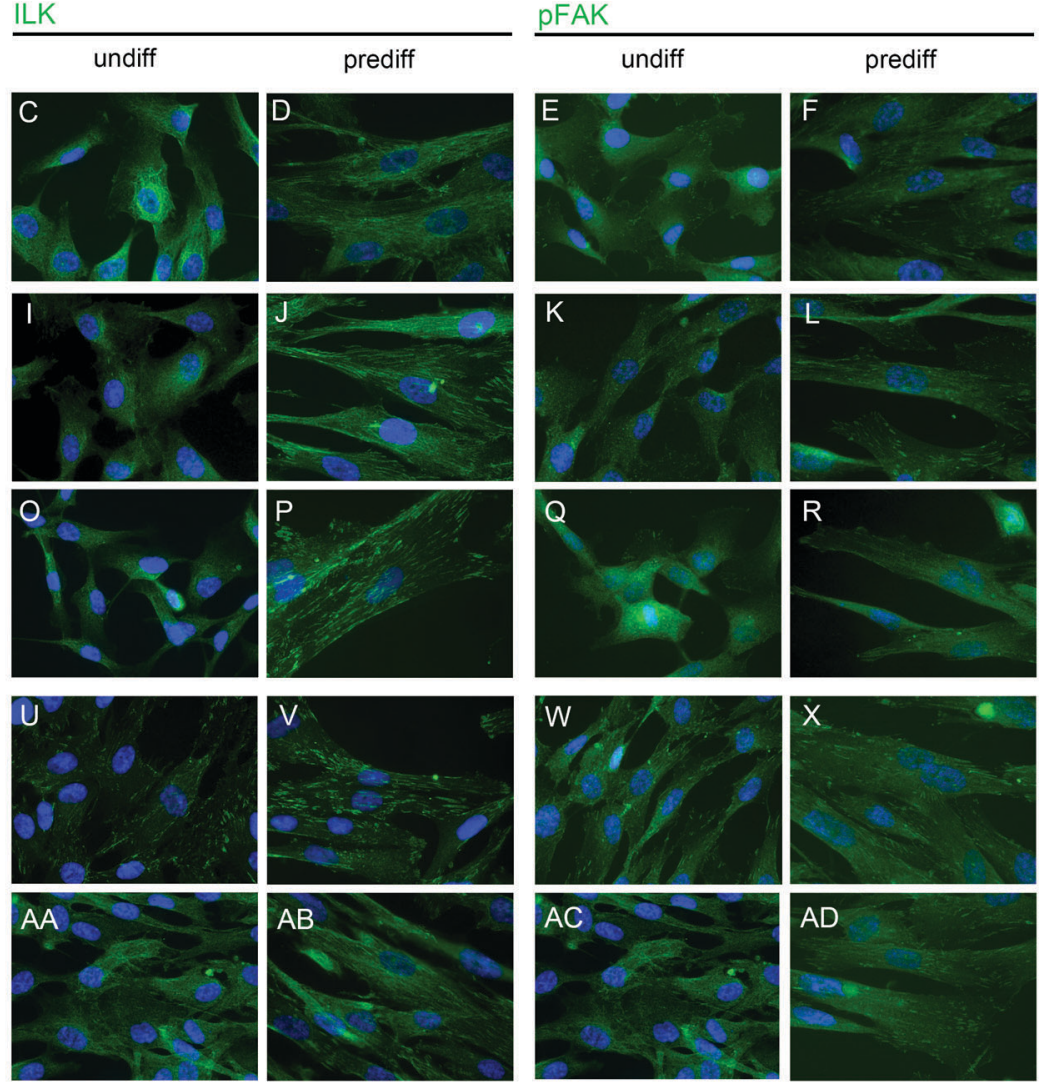

Fig. 3 The mechanosome development is enhanced in CMPCs upon differentiation, and is not promoted by the applied strain. (A-F) At day 0 of straining, undifferentiated (undiff, A, C, E) CMPCs display immature FAs (green) and absence of actin SFs (red), whereas predifferentiated (prediff, B, D, F) CMPCs show a more developed mechanosome, characterized by large FA clusters and SFs. (A) At day 1 (G-R) and day 2 (S-AD) of straining, undifferentiated CMPCs $(G, I, K, M, O, Q, S, U, W, Y, A A, A C)$ show small clusters of vinculin and cytoplasmic expression of ILK and pFAK, indicating immature adhesions. Cortical and cytoskeletal actin, with absence of SFs are observed. In predifferentiated cells ( $H, J, L, N, P, R, T, V, X, Z, A B, A D)$, larger clusters of vinculin, ILK, and pFAK are visible. Actin SFs are present in predifferentiated cells, with thicker fiber bundles in strained samples. In both cell types, unstrained cells display larger FA protein clusters, with more elongated assemblies in strained cells. Scale bar is $100 \mu \mathrm{m}$. ( $n=3$ independent experiments). 
on glass cover-slips. Since vinculin is one of the first adhesion proteins to be recruited to FAs, ${ }^{17,27}$ and actin SFs are responsible for cell contractility, ${ }^{31}$ we investigated the distribution of vinculin and the formation of stress fibers at $1 \mathrm{~h}, 6 \mathrm{~h}$, and $24 \mathrm{~h}$ after seeding. It is well-known that some cell types only develop FA clusters and SFs when cultured on stiff substrates. ${ }^{32-34}$ To verify whether the mechanosome maturation is influenced by the seeding substrate in CMPCs, we analyzed the development of vinculin clusters and SFs in undifferentiated and predifferentiated CMPCs on two collagen IV-coated surfaces: the silicone Bioflex membrane and glass.

During attachment to and spreading on both substrates cell morphology was remarkably different between undifferentiated and predifferentiated CMPCs (Fig. 4). Both on silicone and glass, undifferentiated CMPCs showed a more elongated shape than predifferentiated cells, and displayed faster spreading and less extensive adhesions to the substrate.

On the Bioflex membrane, undifferentiated cells showed an undeveloped mechanosome, with mostly perinuclear expression of vinculin (Fig. 4A, E, I and M), and only cortical and cytoplasmic actin (Fig. 4Q). In predifferentiated cells instead, vinculin was mainly localized around the nucleus and at the cell edges up to $6 \mathrm{~h}$ after plating (Fig. 4B and F), while at $24 \mathrm{~h}$ vinculin clusters were visible especially at the cell edge (Fig. 4J and O). On the silicon surface, SFs (Fig. 4S) were formed in predifferentiated cells, as shown after $48 \mathrm{~h}$ of seeding in Fig. $3 \mathrm{G}$ and H. Undifferentiated CMPCs did not develop the mechanosome even when seeded on glass cover-slips (Fig. 4B, F, J, N and R), whereas predifferentiated cells developed slightly larger vinculin clusters and more prominent stress fiber bundles on glass (Fig. 4D, H, L, P and T), as compared to the silicone substrate. However, the absence of mechanosome in undifferentiated CMPCs was evident on both substrates.

Furthermore, CMPCs displayed a similar mechanosome development on substrates with different composition (collagen I, collagen IV, fibronectin, and gelatin coating on glass, data not shown). This suggests that the development of the mechanosome is also not determined by the substrate composition (i.e., by specific integrin isotypes), but predominantly intrinsic to the cellular differentiation status.

This shows that neither changes in the mechanical properties, nor substrate composition, can induce the maturation of FAs and SFs in undifferentiated CMPCs. The differentiation-induced mechanosome development is an intrinsic property of these cells.

\subsection{Mechanotransduction is activated during early cardiac differentiation}

To further verify the maturation of the mechanosome and the activation of the mechanotransduction pathways, we examined

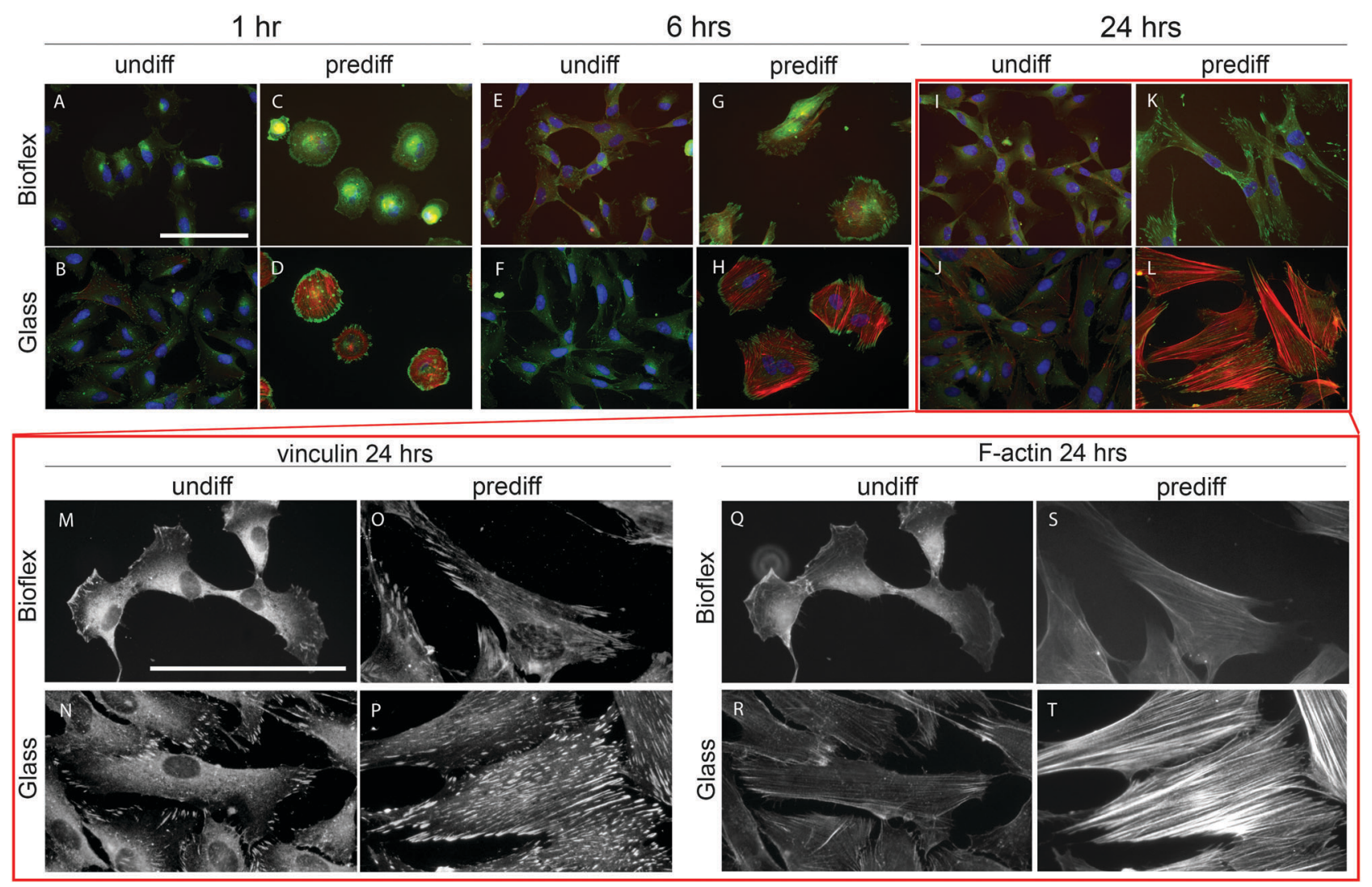

Fig. 4 Undifferentiated and predifferentiated CMPCs show different cell spreading and mechanosome development after seeding. (A-L) Undifferentiated CMPCs (undiff, A, C, E, G, I, K) show immature adhesions and weak expression of actin SFs; predifferentiated CMPCs (prediff: B, D, F, H, J, L) present more pronounced expression of vinculin and stress fiber formation. (M-T) Both cell types show faster spreading on glass $(N, P, R, T)$ than on the silicone Bioflex surface $(M, O, Q, S)$, but the difference in the mechanosome development induced by early differentiation is maintained. Scale bar indicates $100 \mu \mathrm{m}$. 
how different functional components of the mechanosome are activated during CMPC differentiation. FA formation and maturation is initiated by the accumulation and clustering of integrins and FA proteins, such as vinculin and focal adhesion kinase (FAK). Vinculin is well known for its role in cell mechanotransduction; $\beta 1$-integrin has high binding affinity for collagen IV, which is the main ECM component of the cardiac basement membrane. Thus, the expression levels and clustering of vinculin and $\beta 1$-integrin, the cytoskeletal development, and the autophosphorylation of FAK were studied after 1, 7, 8, and 14 days from the start of the differentiation process.

From immunofluorescent images it is evident that undifferentiated CMPCs did not display neither vinculin clusters nor actin SFs, but only cytoplasmic expression of vinculin and actin was observed ( $\mathrm{d}_{\text {diff }} 1$, Fig. $\left.5 \mathrm{~A}\right)$. On $\mathrm{d}_{\text {diff }} 7$ and 8, a few SFs, mainly located close to the cell membrane, and small vinculin clusters could be observed (Fig. 5B and C), whereas at $d_{\text {diff }} 14$ numerous prominent actin SFs throughout the whole cell were present, and large vinculin clusters co-localized with SFs (Fig. 5D). Corresponding to our observations from immunofluorescent images, the results of Western blot analysis on total protein extracts show that the amount of vinculin increased from $\mathrm{d}_{\text {diff }} 1$ onwards to approximately 2 -fold on $\mathrm{d}_{\text {diff }} 14(P<0.05$, Fig. 5E). The amount of $\beta 1$-integrin first slightly increased on $\mathrm{d}_{\text {diff }} 7$, followed by a small decrease on $\mathrm{d}_{\text {diff }} 8$ and $\mathrm{d}_{\text {diff }} 14$ (Fig. 5F).

FA maturation is mainly due to clustering of integrins and FA proteins. Therefore, soluble (S) and cytoskeletal bound (C) protein fractions were analyzed separately. Indeed, the $\mathrm{C}: \mathrm{S}$ ratio of vinculin increased from $0.12 \pm 0.02$ on $\mathrm{d}_{\text {diff }} 1$ to $0.17 \pm 0.06$ on $\mathrm{d}_{\text {diff }} 14$ (Fig. $5 \mathrm{H}$ ), suggesting the incorporation of vinculin into FA complexes during the early phases of CMPC differentiation. Although the $\mathrm{C}: \mathrm{S}$ ratio of vinculin on $\mathrm{d}_{\text {diff }} 7$ and 8 seem to be slightly higher compared to $d_{\text {diff }} 14$, the total amount of vinculin present in the cells was lower at these days, indicating that the formation of FA still increases towards $d_{\text {diff }} 14$. Moreover, integrin clustering at the cell membrane upon CMPC differentiation was shown by an increase in the $\mathrm{C}: \mathrm{S}$ ratio of $\beta 1$-integrin from $0.83 \pm 0.50$ on $\mathrm{d}_{\text {diff }} 1$ to $2.50 \pm 1.21$ on $\mathrm{d}_{\text {diff }} 14$ (Fig. $5 \mathrm{I}$ ). Surprisingly, pFAK was only present in the $\mathrm{S}$ fractions, possibly because the binding of pFAK to the FA complex is not strong
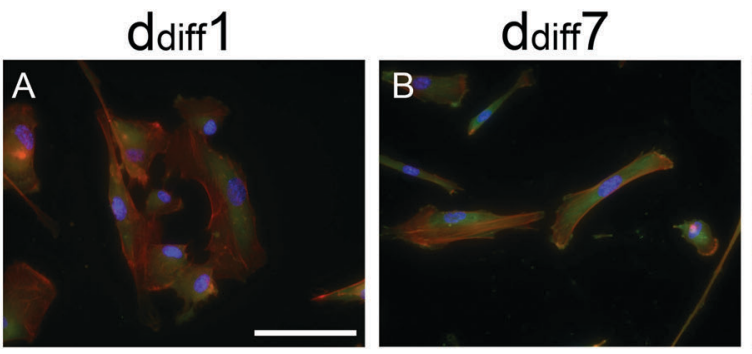

E

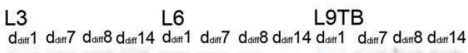

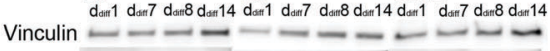
GAPDH - - - - - - - - - -

$\mathrm{F}$
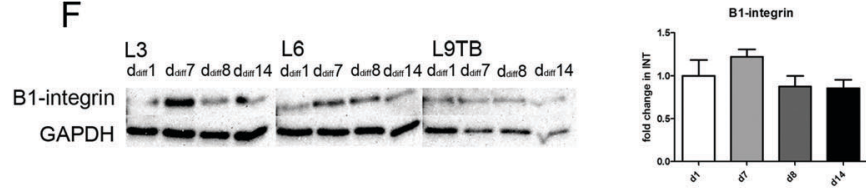
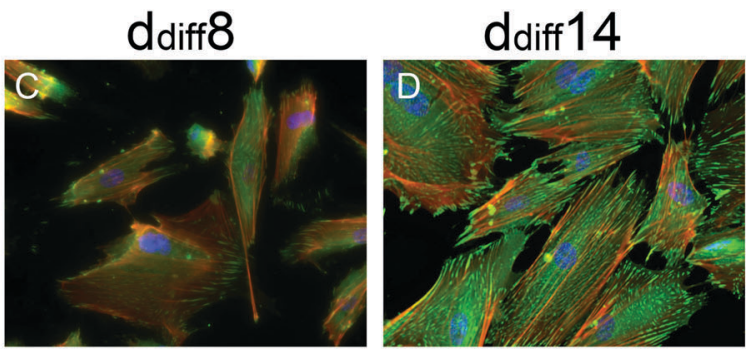

$\mathrm{H}$
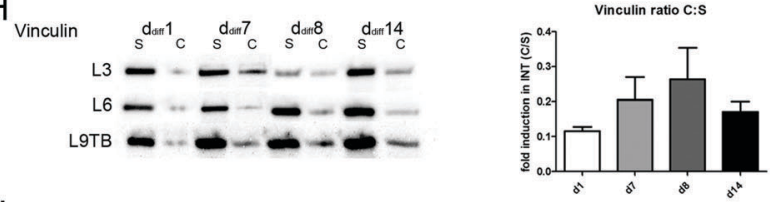

I

B1-integrin
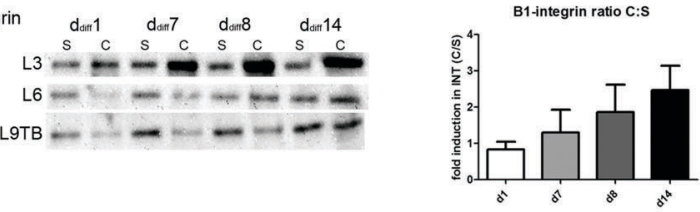

$J$
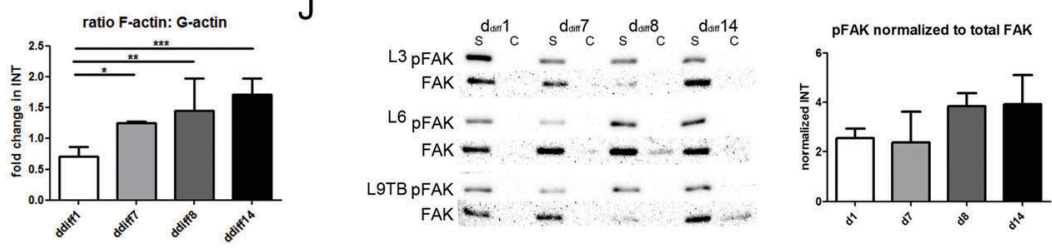

Fig. 5 The CMPC mechanosome components are activated during early differentiation. (A-D) Immunofluorescent stainings of vinculin (green) and actin (red) of CMPCs during induced cardiomyogenic differentiation. The mechanosome starts to form at $d_{\text {diff }} 8$ (C) and is fully developed at $d_{\text {diff }} 14$ (D). $(E-J)$ Western blots for mechanosome components from total protein extracts of CMPCs during differentiation. The total amount of vinculin (E) increased with differentiation, while the levels of total $\beta 1$-integrin stay roughly stable; cytoskeletal to soluble protein fractions (C:S) of vinculin ( $H$ ) and $\beta 1$-integrin (I) increased with differentiation of CMPCs, as well as the ratio of fibrillar to globular actin (G, F-actin:G-actin); the amount of pFAK over the amount of total FAK also increased during differentiation (J). Scale bar is $100 \mu \mathrm{m}$. Data are presented as mean fold change $\pm S D,\left(d_{\text {diff }} 1: n=6, d_{\text {diff }} 7-14: n=4\right)$. ${ }^{\star} P<0.05,{ }^{*} P<0.01$ and ${ }^{* * *} P<0.001$ 
enough and already loosens during the protein extraction and washing steps. Alternatively, the levels of pFAK in the C-fraction were too low to detect with Western blot analysis. However, the level of pFAK normalized to total FAK increased from $2.55 \pm 0.75$ on $\mathrm{d}_{\text {diff }} 1$ to $3.93 \pm 2.36$ on $\mathrm{d}_{\text {diff }} 14$ (Fig. 5J), indicative of the activation of the mechanotransduction pathway.

Finally, the cytoskeletal development during CMPC differentiation was further examined by determining the ratio of fibrillar actin (F-actin) to globular actin (G-actin), derived from the cytoskeletal and soluble protein fractions, respectively. The F- to G-actin ratio showed an increasing trend from $0.71 \pm 0.14$ on $\mathrm{d}_{\text {diff }} 1$ to $1.79 \pm 0.27$ on $\mathrm{d}_{\text {diff }} 14(P<0.001$, Fig. $5 \mathrm{G})$, indicating a shift from globular to fibrillar actin upon cardiomyogenic differentiation of CMPCs, and supporting our data from immunofluorescent stainings, showing the formation of actin fibers during the differentiation process.

Altogether, these results suggest that the mechanosome of CMPCs is activated during early cardiomyogenic differentiation.

\section{Discussion}

In this study, we investigated the mechanosensitivity of CMPCs, and found a relationship between their differentiation state and their ability to respond to mechanical stimuli. Human CMPCs are a promising cell source/target for cardiac regeneration strategies. Understanding the interaction of CMPCs with their niche is therefore essential to identify target mechanisms for possible therapeutic strategies; in particular, mechanical stimuli can have a deep influence on cell behavior in the continuously strained heart. Here, we describe for the first time that the mechanosensitivity of CMPCs is developed upon early cardiomyogenic differentiation, concomitantly with the maturation of the mechanosome. To investigate how CMPCs respond to biomechanical stimuli, we determined the orientation of undifferentiated and predifferentiated cells upon applied uniaxial cyclic strain. We demonstrate that CMPCs are able to respond with strain avoidance to external mechanical stimuli only upon early differentiation. This is in agreement with numerous previous studies and models, describing strain avoidance as a behavior that allows cells to be minimally perturbed by the applied strain, and thus minimize the energy expenditure. ${ }^{10-12}$ Strain avoidance after application of $10 \%$ strain at $1 \mathrm{~Hz}$ has been reported in several other stem cells, e.g. adipose-derived stem cells ${ }^{15}$ bone marrow mesenchymal stem cells, ${ }^{13}$ and bone marrow-derived progenitor cells. ${ }^{14}$ Interestingly, these cells showed clear stress fiber development, ${ }^{14,15,35,36}$ although detailed information regarding the presence of the other components of the mechanosome in these other stem cells is lacking. In contrast to our study, French et al. described strain avoidance of rat c-kit ${ }^{+}$CPCs after $24 \mathrm{~h}$ of applied cyclic strain $(5,10$ and $15 \%)$. They show that rat c-kit ${ }^{+}$CPCs give the strongest strain avoidance response when cultured on fibronectin and collagen I. ${ }^{37}$ However, they do not look at collagen IV, which is the coating substrate used in our study (since it is the main component of the cardiomyocyte basement membrane).
Moreover, the strain avoidance described by French and coworkers (that we only observed in predifferentiated cells) might depend on the different cell source and type used. Overall, this may suggest that the strain response of early cardiac progenitors is dependent on a delicate balance between environmental factors and the differentiation state of the cells. In cardiomyocytes, which are continuously exposed to mechanical cues, response to cyclic strain is dependent on the time of cultivation and on the straining protocol. In rat cardiomyocytes, $20 \%$ elongation at $0.5 \mathrm{~Hz}$ applied $2 \mathrm{~h}^{38}$ or $3 \mathrm{~h}^{39}$ after seeding, led to alignment parallel to the strain direction. Cardiomyocytes aligned parallel to the direction of the stretch also when exposed to strain of $120 \%$ at $0.5 \mathrm{~Hz}$ applied $12 \mathrm{~h}$ after seeding, whereas when previously cultured for $24 \mathrm{~h}$ they oriented perpendicularly to the strain direction after one day of strain. ${ }^{40}$ However, cardiomyocytes failed to change their orientation when strained $72 \mathrm{~h}$ after seeding. ${ }^{39}$ Unfortunately, the different strain amplitudes and rates in these previous studies make it inaccurate to compare the mechanoresponse of cardiomyocytes to that of undifferentiated and predifferentiated CMPCs. Additionally, it is important to mention that the presented results were obtained in a $2 \mathrm{D}$ setup, which is rather different from the in vivo environment.

In this study, the different mechanoresponse of undifferentiated and predifferentiated CMPCs is attributed to the development of the mechanosome, which is linked to the cardiac differentiation status of CMPCs. We show that although undifferentiated CMPCs express $\beta 1$-integrin as well as FA proteins vinculin and (p)FAK, undifferentiated cells do not form stable FA complexes. Upon differentiation, formation of focal adhesion complexes and cytoskeleton development is initiated as shown by clustering of $\beta 1$-integrin and recruitment of vinculin at the FA sites, and a shift from globular to fibrillary actin. In line with our findings, the connection between differentiation and stress fiber development, has previously been described. ${ }^{41,42}$ Jacot et al. ${ }^{43}$ suggested that pluripotent stem cells start to express and activate their mechanotransduction pathway during the process of cardiogenesis. Related to other cell types, a study by Mack et $a l .{ }^{41}$ showed that Rho kinase (ROCK), whose activation by RhoA is responsible for actin polymerization and stress fiber formation, has a crucial role in the regulation of differentiation markers in smooth muscle cell. Similarly, it has been shown that $\beta 1$-integrin deficient cardiac precursors display impaired cardiac specification and formation of sarcomeric structures. ${ }^{44}$ These previous studies support our suggestion that differentiation is responsible for the maturation of the mechanosome in CMPCs. Furthermore, in undifferentiated CMPCs the mechanosome development is neither induced by changed mechanical properties of the substrate, nor by applying strain. The more prominent mechanosome observed in predifferentiated CMPCs seeded on glass as compared to silicone represents a behavior that has extensively been described by a number of papers, showing that a stiffer seeding substrate induces the formation of more static (larger) FAs and a more organized cytoskeleton. ${ }^{32-34}$ Moreover, each seeding substrate might induce a different organization of the collagen coating, and therefore different distribution of the cellular adhesion sites. ${ }^{45}$ However, undifferentiated CMPCs 
did not succeed to develop FAs and SFs on none of the used substrates, and the difference between the mechanosome in the two cell types was maintained both on silicone and on glass. This indicates that undifferentiated CMPCs are not able to develop a mechanosome, regardless of the seeding substrate.

We found that cyclic loading did not induce the mechanosome development in undifferentiated CMPCs. Similarly, cyclic strain did not seem to enhance the maturation of FAs and SFs even in predifferentiated cells. Interestingly, when CMPCs were cultured statically on the Bioflex well-plate (unstrained cells), both undifferentiated and predifferentiated cells seemed to develop slightly larger, more static adhesions than strained samples, as demonstrated by clustering of vinculin (at day 1 only), ILK and, to a minor extent, pFAK. Although it is known that application of force typically results in FA strengthening in a seconds-to-minutes timescale (catch-bonds), ${ }^{46-48}$ it appears that in cells that are cyclically strained, continuously and relatively quickly $(0.5 \mathrm{~Hz})$, the formation of stable adhesions is impaired by the mechanical loading, as FAs undergo a faster assembly/disassembly process. ${ }^{29,49}$

Taken together, our data show that undifferentiated CMPCs do not form stable FAs and have no developed actin cytoskeleton, and thus have an impaired mechanosome. The mechanosome development in CMPCs is intrinsically connected with differentiation, and cannot be induced neither by changing the substrate type or composition, nor by applying cyclic strain. With differentiation, CMPCs start to develop SFs and consequently mature focal adhesions, along with the ability to respond to cyclic strain, indicating mechanosensing development. The presented results might suggest that resident undifferentiated CMPCs are shielded from the external mechanical cues due to the lack of mechanosome. This might be a protective effect of the undifferentiated CMPCs themselves. With an impaired mechanosensing apparatus these cells may remain in undifferentiated and quiescent state while continuously exposed to mechanical cues in the beating heart. Predifferentiated CMPCs instead are more prone to align and integrate with the host cells and tissue, and might thus represent a more promising source for cardiac regeneration therapy.

\section{Conclusions}

In conclusion, our findings indicate that the cell mechanosensing apparatus in direct contact with the ECM, or mechanosome, is developed during cardiomyogenic differentiation in CMPCs, regardless of the used substrate. Stress fiber development and focal adhesion maturation enable predifferentiated cells to sense and respond to uniaxial cyclic strain, by aligning perpendicularly to the direction of the strain after two days. On the contrary, the lack of a developed mechanosome in undifferentiated CMPCs shields them from external mechanical stimuli. Moreover, actin stress fiber formation and FA maturation cannot be induced in undifferentiated CMPCs only by mechanical stimulation, but it requires (early) cardiomyogenic differentiation.

\section{Acknowledgements}

Dr Sotiris Korossis from Hannover Medical School and Dr Paola Aguiari from University of Padova are thankfully acknowledged for the fruitful discussion. This research was funded by the People Program (Marie Curie Actions) of the European Union's Seventh Framework Program FP7-People-2012-ITN “TECAS”, under grant agreement no. 317512. Part of the research described here was supported by a grant of the Dutch Heart Foundation (DHF-2014T013 and DHF-2008T092).

\section{References}

1 A. Leri, J. A. N. Kajstura and P. Anversa, Physiol. Rev., 2005, 86, 1373-1416.

2 A. M. Smits, L. W. van Laake, K. den Ouden, C. Schreurs, K. Szuhai, C. J. van Echteld, C. L. Mummery, P. A. Doevendans and M.-J. Goumans, Cardiovasc. Res., 2009, 83, 527-535.

3 P. van Vliet, M.-J. Goumans, P. A. Doevendans and J. P. G. Sluijter, J. Cell. Mol. Med., 2012, 16, 1669-1673.

4 N. A. M. Bax, M. H. van Marion, B. Shah, M.-J. Goumans, C. V. C. Bouten and D. W. J. van der Schaft, J. Mol. Cell. Cardiol., 2012, 53, 497-508.

5 V. Barron, C. Brougham, K. Coghlan, E. McLucas, D. O’Mahoney, C. Stenson-Cox and P. E. McHugh, J. Mater. Sci.: Mater. Med., 2007, 18, 1973-1981.

6 H. Ngu, Y. Feng, L. Lu, S. J. Oswald, G. D. Longmore and F. C. P. Yin, Ann. Biomed. Eng., 2010, 38, 208-222.

7 F. Boccafoschi, M. Bosetti, S. Gatti and M. Cannas, Cell Adhes. Migr., 2007, 1, 124-128.

8 S. Jungbauer, H. Gao, J. P. Spatz and R. Kemkemer, Biophys. J., 2008, 95, 3470-3478.

9 P. R. Standley, A. Cammarata, B. P. Nolan, C. T. Purgason and M. A. Stanley, Am. J. Physiol.: Heart Circ. Physiol., 2002, 283, H1907-H1914.

10 A. Livne, E. Bouchbinder and B. Geiger, Nat. Commun., 2014, 5, 3938.

11 A. Tondon, H. J. Hsu and R. Kaunas, J. Biomech., 2012, 45, 728-735.

12 H.-J. Hsu, C.-F. Lee and R. Kaunas, PLoS One, 2009, 4, e4853.

13 J. S. Park, J. S. F. Chu, C. Cheng, F. Chen, D. Chen and S. Li, Biotechnol. Bioeng., 2004, 88, 359-368.

14 D. W. Hamilton, T. M. Maul and D. A. Vorp, Tissue Eng., 2004, 10, 361-369.

15 W.-C. C. Lee, T. M. Maul, D. A. Vorp, J. P. Rubin and K. G. Marra, Biomech. Model. Mechanobiol., 2007, 6, 265-273.

16 M. Chrzanowska-Wodnicka and K. Burridge, J. Cell Biol., 1996, 133, 1403-1415.

17 C. K. Choi, M. Vicente-manzanares, J. Zareno, A. Leanna, A. Mogilner, A. R. Horwitz and B. Engineering, Nat. Cell Biol., 2008, 10, 1039-1050.

18 F. M. Pavalko, S. M. Norvell, D. B. Burr, C. H. Turner, R. L. Duncan and J. P. Bidwell, J. Cell. Biochem., 2003, 88, 104-112.

19 J. P. Bidwell and F. M. Pavalko, Clin. Rev. Bone Miner. Metab., 2010, 8, 213-223. 
20 P. Kanchanawong, G. Shtengel, A. M. Pasapera, E. B. Ramko, M. W. Davidson, H. F. Hess and C. M. Waterman, Nature, 2010, 468, 580-584.

21 R. O. Hynes, Cell, 2002, 110, 673-687.

22 M. A. Schwartz, Cold Spring Harbor Perspect. Biol., 2010, 2, 1-13.

23 H. Chen, D. M. Cohen, D. M. Choudhury, N. Kioka and S. W. Craig, J. Cell Biol., 2005, 169, 459-470.

24 S. A. Wickström, A. Lange, E. Montanez and R. Fässler, EMBO J., 2010, 29, 281-291.

25 M. J. Goumans, T. P. de Boer, A. M. Smits, L. W. van Laake, P. van Vliet, C. H. G. Metz, T. H. Korfage, K. P. Kats, R. Hochstenbach, G. Pasterkamp, M. C. Verhaar, M. A. G. van der Heyden, D. de Kleijn, C. L. Mummery, T. A. B. van Veen, J. P. G. Sluijter and P. A. Doevendans, Stem Cell Res., 2008, 1, 138-149.

26 A. M. Smits, P. van Vliet, C. H. Metz, T. Korfage, J. P. Sluijter, P. A. Doevendans and M.-J. Goumans, Nat. Protoc., 2009, 4, 232-243.

27 A. Carisey and C. Ballestrem, Eur. J. Cell Biol., 2011, 90, 157-163.

28 A. Carisey, R. Tsang, A. M. Greiner, N. Nijenhuis, N. Heath, A. Nazgiewicz, R. Kemkemer, B. Derby, J. Spatz and C. Ballestrem, Curr. Biol., 2013, 23, 271-281.

29 B. D. Hoffman, C. Grashoff and M. a Schwartz, Nature, 2011, 475, 316-323.

30 R. Zaidel-Bar, C. Ballestrem, Z. Kam and B. Geiger, J. Cell Sci., 2003, 116, 4605-4613.

31 S. Tojkander, G. Gateva and P. Lappalainen, J. Cell Sci., 2012, 125, 1855-1864.

32 D. E. Discher, P. Janmey and Y.-L. Wang, Science, 2005, 310, 1139-1143.

33 A. M. Pasapera, I. C. Schneider, E. Rericha, D. D. Schlaepfer and C. M. Waterman, J. Cell Biol., 2010, 188, 877-890.

34 A. Huttenlocher and A. R. Horwitz, Cold Spring Harbor Perspect. Biol., 2011, 3, 1-16.

35 D. E. Discher, D. J. Mooney and P. W. Zandstra, Science, 2009, 324, 1673-1677.
36 A. J. Engler, S. Sen, H. L. Sweeney and D. E. Discher, Cell, 2006, 126, 677-689.

37 K. M. French, J. T. Maxwell, S. Bhutani, S. Ghosh-choudhary, M. J. Fierro, T. D. Johnson, K. L. Christman, W. R. Taylor and E. Michael, Stem Cells Int., 2016, DOI: 10.1155/2016/8364382.

38 M. Yamane, T. Matsuda, T. Ito, Y. Fujio, K. Takahashi and J. Azuma, Biochem. Biophys. Res. Commun., 2007, 353, 1023-1027.

39 T. Matsuda, K. Takahashi, T. Nariai, T. Ito, T. Takatani, Y. Fujio and J. Azuma, Biochem. Biophys. Res. Commun., 2005, 326, 228-232.

40 K. Kada, K. Yasui, K. Naruse, K. Kamiya and I. Kodama, J. Mol. Cell. Cardiol., 1999, 259, 247-259.

41 C. P. Mack, A. V. Somlyo, M. Hautmann, A. P. Somlyo and G. K. Owens, J. Biol. Chem., 2001, 276, 341-347.

42 N. Sandbo, a. Lau, J. Kach, C. Ngam, D. Yau and N. O. Dulin, Am. J. Physiol.: Lung Cell. Mol. Physiol., 2011, 301, L656-L666.

43 J. G. Jacot, J. C. Martin and D. L. Hunt, J. Biomech., 2010, 43, 93-98.

44 R. Fässler, J. Rohwedel, V. Maltsev, W. Bloch, S. Lentini, K. Guan, D. Gullberg, J. Hescheler, K. Addicks and A. M. Wobus, J. Cell Sci., 1996, 2999, 2989-2999.

45 B. Trappmann, J. E. Gautrot, J. T. Connelly, D. G. T. Strange, Y. Li, M. L. Oyen, M. a Cohen Stuart, H. Boehm, B. Li, V. Vogel, J. P. Spatz, F. M. Watt and W. T. S. Huck, Nat. Mater., 2012, 11, 642-649.

46 C. G. Galbraith, K. M. Yamada and M. P. Sheetz, J. Cell Biol., 2002, 159, 695-705.

47 D. Riveline, E. Zamir, N. Q. Balaban, U. S. Schwarz, T. Ishizaki, S. Narumiya, Z. Kam, B. Geiger and A. D. Bershadsky, J. Cell Biol., 2001, 153, 1175-1185.

48 N. Q. Balaban, U. S. Schwarz, D. Riveline, P. Goichberg, G. Tzur, I. Sabanay, D. Mahalu, S. Safran, A. Bershadsky, L. Addadi and B. Geiger, Nat. Cell Biol., 2001, 3, 466-472.

49 B. Chen, R. Kemkemer, M. Deibler, J. Spatz and H. Gao, PLoS One, 2012, 7, e48346. 